\title{
TRADUZIR: REFLEXÕES SOBRE A TEORIA E PRÁTICA DA TRADUÇÃO CRIATIVA
}

Arlete Cavaliere*

RESUMO: O presente artigo apresenta e discute algumas proposições teóricas sobre a arte da tradução literária.

Palavras-chave: tradução, criação, crítica literária.

Comecemos por uma colocação de Roman Jakobson um tanto ameaçadora: "a prática e a teoria da tradução apresentam problemas complexos, e de quando em quando, fazem-se tentativas de cortar o nó górdio, proclamando o dogma da impossiilidade da tradução."

Este é um fantasma que persegue a tarefa de todo tradutor. No entanto, no mesmo artigo "Aspectos linguísticos da tradução" Jakobson afirma que toda experiência cognitiva pode ser traduzida e classificada em qualquer lingua existente. Onde houver uma deficiência, a terminologia poderá ser modificada por empréstimos, neologismos, transferências semânticas e finalmente, por circunlóquios. O fato é que seja

(*) Professora de Teatro e Cultura Russa e coordenadora do Curso de Russo da FFLCH-USP.

(1) JAKOBSON, Roman. "Aspectos linguísticos da tradução", in Linguística e comunicação. Cultrix, São Paulo, 1970. 
qual for a forma de interpretação de um signo verbal, a comunicação pode ser sempre resgatada, recuperada.

Jakobson distingue três maneiras de interpretar um signo verbal: ele pode ser traduzido em outros signos da mesma língua (tradução intralingual); em outra língua (tradução interlingual) e em outro sistema de símbolos não-verbais (tradução intersemiótica).

No caso da tradução interlingual que consiste na interpretação dos signos verbais por meio de alguma outra língua, não há comumente equivalência completa entre as unidades de código, ao passo que as mensagens podem servir como interpretações adequadas das unidades de código ou mensagens estrangeiras.

A ausência de certos processos gramaticais na língua (ou mesmo na linguagem) para a qual se traduz nunca impossibilita uma tradução literal da totalidade da informação conceitual contida no original. Se alguma categoria gramatical não existe numa língua dada, seu sentido pode ser traduzido nessa língua com a ajuda de meios lexicais.

Portanto, em sua função cognitiva, nos diz Jakobson, a linguagem depende muito pouco do sistema gramatical, porque a definição de nossa experiência está numa relação complementar com as operações metalinguísticas - o nível cognitivo da linguagem não só admite, mas exige a interpretação por meio de outros códigos, a recodificação, isto é, a tradução. Assim, a hipótese da impossibilidade de se traduzir dados cognitivos parece inviável e até contraditória.

Mas como proceder quando as categorias gramaticais têm um teor semântico elevado? Como traduzir quando nos encontramos diante de um universo que Jakobson chamou de "mitologia verbal": nos sonhos, na magia, na poesia?

É aqui que a questão da tradução se complica e se presta muito mais a discussões. E diante do tradutor surge imediatamente o fantasma da intraduzibilidade da obra de arte. 
O problema se torna mais complexo se considerarmos com Jakobson que a dificuldade do tradutor em preservar certos simbolismos de determinados sistemas gramaticais se choca muitas vezes com a falta de pertinência dessa dificuldade do ponto de vista cognitivo.

Como resolver a decepção de uma criança russa que ao ler uma tradução de contos alemães, fica estupefata ao descobrir que a Morte, seguramente uma mulher (em russo 'smert', feminino), é representada por um velho (em alemão 'der Tod', masculino)?

Certas divergências de categorias gramaticais podem anular assim toda uma identificação simbólica numa certa comunidade linguística. Mas se uma língua nem sempre pode ser reproduzida de maneira idêntica quando traduzida por outra língua, o que fazer diante de uma obra literária quando as equações verbais são elevadas à categoria de princípio construtivo do texto?

Sabemos que na poesia as categorias sintáticas e morfológicas, as raizes, os afixos, os fonemas e seus componentes, enfim, todos os constituintes do código verbal são confrontados, justapostos, colocados em relação de contiguidade de acordo com o princípio de similaridade e de contraste, e transmitem assim uma significação própria.

A própria semelhança fonológica é sentida como um parentesco semântico e reina na arte poética. Como traduzí-la?

Haroldo de Campos, como se sabe, discute vários aspectos do problema, ${ }^{2}$ valendo-se, em dado momento, da teoria de base semiótica e teórico-informativa do filósofo e crítico Max Bense. A sua distinção entre "informação documentária", "infomação semântica" e "informação estética" nos parece bastante elucidativa.

(2) Cf. especialmente CAMPOS, Haroldo de. "Da tradução como criação e como crítica", in Metalinguagem, Vozes, Petrópolis, 1967. 
A "informação documentária" reproduz algo observável, é uma sentença empírica, uma sentença registro. A "informação semântica" já transcende a "documentária", pois vai além do horizonte do observado, acrescentando algo que em si mesmo não é observável, um elemento novo, como por exemplo, o conceito de falso e verdadeiro. É todo o universo de significações que está por trás da informação.

Já a "informação estética" transcende a semântica, no que concerne à imprevisibilidade, à surpresa, à improbabilidade da ordenação de signos.

É uma certa "fragilidade" da informação estética, responsável talvez pelo fascínio da obra de arte, que impede as diversas codificações ou as várias maneiras de transmitir que as informações documentária e semântica permitem. Isto porque a informação estética não pode ser codificada senão pela forma em que foi transmitida pelo artista, pois qualquer alteração na sequência de signos, por menor que seja, pode perturbar sua realização estética. Daí a conclusão de que em cada língua há uma outra informação estética para informações semanticamente iguais.

Quer estejamos no domínio da prosa, quer no domínio da poesia, a questão fundamental que se coloca é: seria a literatura intraduzível?

Muito já se falou sobre a distinção entre prosa e poesia e o caráter da palavra como "coisa" na poesia. Para Sartre, por exemplo, a "mot-chose" na poesia se opõe a "mot-signe" na prosa. A propósito dos versos de Rimbaud:

"O saisons! ô châteaux!

Quelle âme est sans défauts",

Sartre escreve: "Personne n'est interrogé, personne n'interroge: le poète est absent. Et l'interrogation ne comporte pas de réponse ou plutôt elle est sa propre réponse. Est-ce donc une fausse interrogation? Mais il serait absurde de croire 
que Rimbaud a "voulu dire": tout le monde a ses défauts. Comme disait Breton de Saint-Pol-Roux: "S'il avait voulu le dire, il l'aurait dit". Et il n'a pas non plus voulu dire autre chose. Il a fait une interrogation absolue; il a conféré au beau mot d'âme une existence interrogative. Voilá l'interrogation devenue chose, comme l'angoisse du Tintoret était devenue jaune. Ce n'est plus une signification, c'est une substance..."

É claro, portanto, que o problema da intraduzibilidade da obra literária se afigura mais agudo quando estamos diante da poesia. Mas a dicotomia prosa x poesia, nestes termos, se mostra insubsistente, pelo menos como critério absoluto, se levarmos em conta textos em prosa que conferem primacial importância ao tratamento da palavra como objeto, ficando, nesse sentido, ao lado da poesia.

Por exemplo, "Memórias Sentimentais de João Miramar" e "Serafim Ponte Grande" de Oswald de Andrade; "Macunaima" de Mário de Andrade; "Grande Sertão: Veredas" de Guimarães Rosa, para ficarmos apenas na literatura brasileira, postulariam "a priori", tanto como a poesia, a impossibilidade da tradução. Assim, nos parece mais viável a substituição dos conceitos de prosa e poesia pelo de texto.

Mas a questão não se resolve: como então traduzir textos criativos, uma vez que, neste caso, precisamos, antes de mais nada, transpor em outra língua uma "informação estética", além da "informação semântica"?

A tarefa é dificil. E a saída possivel é a tentativa de uma transposição criativa: "teremos em outra língua uma outra informação estética, autônoma, mas ambas estarão ligadas entre si por uma relação de isomorfia: serão diferentes enquanto linguagem, mas, como os corpos isomorfos, cristalizar-se-ão dentro de um mesmo sistema” (H. Campos).

(3) Apud Haroldo de Campos, ob. cit., p. 23. 
A tradução de textos criativos deverá ser sempre recriação, ou criação paralela, autônoma, porém recíproca, onde o que se busca não é apenas o significado, mas o próprio signo, ou seja, sua fisicalidade, sua materialidade.

Walter Benjamin em seu artigo "La tâche du traducteur" analisa com muita propriedade o problema sob uma nova luz: a de uma filosofia da linguagem. Segundo o pensador alemão, existe uma estrutura oculta da linguagem que é universal e comum a todos os homens. As diferenças entre as línguas são essencialmente superficiais. E a tradução é viável devido a este plano mais profundo e universal da linguagem, do qual todas as gramáticas derivam e que pode ser localizado e reconhecido em todo o idioma humano.

Para Walter Benjamin a tradução assume um caráter profundamente filosófico, ético e até mágico e mítico, através do conceito de "Linguagem Universal" ou "Linguagem Pura": a tradução pode ser possivel e impossivel ao mesmo tempo; trata-se de uma antinomia dialética que nasce do fato de que todas as línguas são fragmentos de uma só "linguagem pura": um "Logos"que faz o discurso ser expressivo, mas não é visível explicitamente em nenhuma lingua.

Traduzir de uma língua A em outra B implica a existência de uma terceira, presente e ativa, que evidencia os traços desse "discurso puro" que precede e se encontra subliminar em todas as línguas. Isso equivale a dizer que todos os seres humanos expressam as mesmas coisas e que a voz humana nasce das mesmas esperanças, dos mesmos medos, embora através de diferentes palavras.

A tradução, portadora dos germes dessa "Linguagem Pura", se situaria para o teórico alemão a meio-caminho entre a criação literária e a teoria.

(4) BENJAMIN, Walter. "La tâche du traducteur", in Mythe et violence. Denöel (Lettres Nouvelles), Paris, 1971. 
Dessa forma, o problema da tradução engendra um aspecto mais profundo: o da arte de traduzir. E, como já se disse, a demonstração da impossibilidade teórica da tradução implicaria a assertiva de que a tradução é arte, elegendo-a assim à categoria estética como criação. E ainda: se o objetivo de toda arte é algo impossivel, isto é, exprimir o inexprimível, reproduzir o irreproduzivel, fixar o infixável, então por que não se supor possivel traduzir o intraduzivel ?

Se a tradução de textos artísticos é antes de tudo uma vivência interior do mundo e da técnica do traduzido, uma desmontagem e uma remontagem da máquina da criação, "aquela fragílima beleza aparentemente intangivel que nos oferece o produto acabado numa língua estranha", como bem coloca Haroldo de Campos, então a tradução também é crítica.

Ezra Pound considerava a tradução como uma modalidade da crítica, na medida em que corresponde às suas funções mais importantes:

1. tentativa teórica de antecipar a criação;

2. escolha: ordenação geral e expurgo do já feito, eliminação de repetições, ordenação do conhecimento de modo que o próximo homem (ou geração) possa o mais rapidamente encontrar-lhe a parte viva e perca menos tempo possivel com questões obsoletas.

Nessa linha de raciocínio, a crítica via tradução pode dar nova vida ao passado literário. Quando tentamos lançar a tradição à luz da modernidade, o que procuramos, antes de mais nada, é uma nova digestão capaz de assimilar obras do passado convenientemente, através de um novo olho críticocriativo, como quer T.S.Eliot, capaz de ver o passado em seu lugar com suas definidas diferenças em relação ao presente e, no entanto, tão cheio de vida que deverá parecer tão presente para nós como o próprio presente. 
Assim, a tradução de textos criativos deve perseguir, antes de tudo, a fidelidade ao "espírito" e ao "clima" do traduzido, ao "tom" do original, característico e expressivo dentro de uma determinada tradição literária.

Essa busca do "tom" do original, muitas vezes pode nos fazer desviar das palavras, se elas o obscurecem, mas é necessário, sempre que possivel, buscar efeitos ou variantes que o original autoriza em sua linha de invenção.

Aqui novamente devemos pensar na teoria de Walter Benjamin quando discute dois conceitos fundamentais da teoria da tradução: a fidelidade e a liberdade, conceitos que devem ser analisados com muito cuidado se o que se pretende é uma tradução que visa mais do que uma simples restituição do sentido.

Uma tradução que busca fielmente cada palavra não pode jamais restituir plenamente o sentido mais profundo da palavra no original, pois devemos levar em consideração que as palavras têm também uma certa tonalidade afetiva que não pode ser desprezada. Traduzir é, pois, mais do que comunicar: a tradução é uma forma própria, e a tarefa do tradutor é também uma tarefa própria, diferente da do escritor.

No artigo "Hybris da Tradução - Hybris da análise", Boris Schnaiderman, demonstrando o seu "modus operandi" para a análise e tradução da epígrafe em versos da novela "A Dama de Espadas" de A.S. Púchkin, salienta a necessidade de uma transcriação, através da qual o tradutor deve necessariamente exceder os lindes de sua lingua, estranhando-lhe o léxico, "recompensando a perda aqui com uma intromissão inventiva acolá, até que o desatine e desapodere aquela última Hybris, que é transformar o original na tradução de sua tradução."

Já se falou que traduzir é a maneira mais atenta de ler, pois é ler com acuidade, é penetrar melhor a obra. Este deve

(5) SCHNAIDERMAN, B. "Hybris da Tradução", in Revista Colóquio/Letras, Lisboa, Setembro. 
ser também o objetivo do tradutor: um exercício de intelecção e, através dele, uma operação de crítica ao vivo. Talvez seja a melhor leitura que se pode fazer de um texto literário: traduzindo-o estaremos penetrando nos seus mecanismos e engrenagens mais intimos.

\section{Bibliografia}

BENJAMIN, Walter. La tâche du traducteur, in Mythe et violence. Paris: Denöel (Lettres Nouvelles), 1971.

CAMPOS, Haroldo de. Da tradução como criação e como crítica, in Metalinguagem. Petrópolis: Vozes, 1967.

. A operação do texto. São Paulo: Perspectiva, 1976.

JAKOBSON, Roman. Aspectos linguísticos da tradução, in Linguística e comunicação. São Paulo: Cultrix, 1970.

SCHNAIDERMAN, Boris. Hybris da Tradução-Hybris da análise, in Revista Colóquio/Letras. Lisboa: Setembro, 1980.

RÉSUMÉ: Le présent article se propose d'exposer et de discuter quelques propositions teóriques sur la traduction littéraire.

Mots-clés: traduction, création, critique littéraire. 